\title{
A educação permanente em saúde como estratégia de formação de gestores municipais: o Fórum de Educação Permanente de Bragança Paulista
}

\author{
Wanda Nascimento dos Santos Sato ${ }^{1}$, \\ Luiz Carlos de Oliveira Cecílio² e \\ Rosemarie Andreazza ${ }^{3}$
}

RESUMO: Com o objetivo de avaliar a contribuição da educação permanente na formação dos gestores de saúde de uma região do Estado de São Paulo, realizou-se um estudo de caso do Fórum de Educação Permanente para Gestores Municipais de Saúde. A observação participante dos pesquisadores apontou três dimensões de resultados: a primeira, de autoanálise dos gestores, ao aumentar a reflexão sobre o "fazer gestão" de forma compartilhada; a segunda, de caráter pedagógico, aumentando a "caixa de ferramentas” compostas por saberes operatórios para a gestão; e a terceira, política, ao melhorar a compreensão do SUS como política no quadro mais amplo do papel do Estado. A melhor articulação dos gestores municipais, aumentando sua capacidade de mobilização junto ao gestor estadual, foi um resultado positivo. A rotatividade dos gestores, as interferências políticas locais e a baixa capacidade de respostas do órgão regional da Secretaria de Estado da Saúde foram dificultadores ao sucesso da experiência.

PALAVRAS-CHAVE: educação permanente, gestão em saúde, municipalização, Sistema Único de Saúde, descentralização.

ABSTRACT: The aim of this paper was to assess the contribution of permanent education towards the formation of health managers in a given region of Sao Paulo state, Brazil, a case study of the Permanent Education Forum for Local Health Managers (Fórum de Educação Permanente para Gestores Municipais de Saúde). The participating observation of the researchers allowed checking the results within three dimensions: the managers self-analysis as the reflection on their own work is increased; a pedagogical feature, increasing the comprises operational knowledge on management; and the political feature, which broadens the understanding about the Brazilian Health Care System. The enhanced articulation of local managers, increasing their capacity to make pressure against the state manager was a positive result. The managers'turnover, the local political interferences as well as the low capacity to provide answers on part of the regional public entity were stumbling-blocks to the success of this experience.

KEYWORDS: permanent education, health management, municipalization, Brazilian Health Care Service, decentralization.

\footnotetext{
Mestre em Saúde Coletiva. Enfermeira do Departamento de Medicina Preventiva da Universidade Federal de São Paulo (Unifesp). E-mail: wandasato@bol.com.br.

2 Doutor em Saúde Coletiva. Professor Adjunto Livre-Docente do Departamento de Medicina Preventiva da Universidade Federal de São Paulo (Unifesp). E-mail: cecilioluiz@uol.com.br.

3 Doutora em Saúde Pública. Professora Adjunta do Departamento de Medicina Preventiva da Universidade Federal de São Paulo (Unifesp). E-mail: ra48@terra.com.br.
} 


\section{Introdução}

Os gestores municipais de saúde como atores estratégicos na atual etapa de implantação do SUS e os desafios de sua formação

Criado pela Lei Federal 8080/88, o Sistema Único de Saúde (SUS) tem experimentado importantes avanços, mas também vivido novos e crescentes desafios para cumprir seus princípios e diretrizes, na proporção em que se avança em sua implementação e consolidação em todo o território nacional, em particular a partir do processo de municipalização ocorrido na década de 1990.

Desde a sua criação e da edição dos subsequentes instrumentos de regulamentação, os municípios têm visto aumentar suas responsabilidades em relação à organização e operacionalização dos sistemas locais de saúde. Esse movimento de descentralização, de conjunto importante de responsabilidades e de recursos das esferas superiores do sistema para os municípios é reconhecido, hoje, como uma verdadeira reforma setorial do Estado (LEVCOVITZ, LIMA e MACHADO, 2001; NEPESS, 2006; PESTANA e MENDES, 2004).

Da Norma Operacional Básica 01/1993 até o Pacto pela Saúde, editado em 2006, que sintetiza a mais recente política do Ministério da Saúde ao estabelecer as atribuições dos vários entes governamentais na configuração do SUS, vem sendo reforçado o protagonismo dos municípios na execução da política de saúde. O fato de os vários municípios apresentarem histórias e trajetórias muito distintas entre si de implantação dos seus sistemas locais de saúde aponta novos desafios na construção do SUS, em particular a formação de seus gestores locais (SCATENA e TANAKA, 2001; SILVA, 2001; VIANA et al., 2002; BRASIL, 1993 e 2006; CECILIO et al., 2007).

A diversidade dos perfis dos gestores municipais de saúde, somada à complexidade que a configuração do sistema vai assumindo, tem demandado estratégias de formação para esses atores fundamentais para a consolidação e aprimoramento do SUS. Levcovitz et al. (2001), em artigo sobre as dificuldades na implementação do SUS, destacam os seguintes pontos relativos aos "recursos humanos": diferentes formações dos profissionais de saúde; heterogeneidade das equipes técnicas; dificuldade de contratação; pressão para redução de gastos com pessoal e distribuição de forma heterogênea dos profissionais de saúde pelo território nacional. Com relação à organização do sistema, destacam a heterogeneidade na capacidade de gestão nos diferentes níveis de governo, além dos conflitos e competitividade nas relações entre tais níveis.

CADERNOS GESTÃo PÚBLICA E CIDADANIA, V. 14, N. 55 - JUL./DEZEMBRO DE 2009 
Com o objetivo de melhorar a formação de gestores municipais, foi criado, em 2005, na Região de Bragança Paulista, o Fórum de Educação Permanente (FEP), por iniciativa do então Departamento Regional de Saúde de Campinas (DRS-VII), órgão regional da Secretaria Estadual de Saúde de São Paulo (SES-SP).

A Região de Bragança Paulista apresenta um dos Índices de Desenvolvimento Humano (IDH-M) mais baixos do Estado de São Paulo. É heterogênea quanto ao tamanho das populações, dimensão territorial e tipo de atividade econômica desenvolvida pelos vários municípios, prevalecendo, no entanto, aqueles com menos de 15 mil habitantes. Apenas duas cidades têm mais de 100 mil habitantes. Duas cidades da região possuem menos de cinco mil habitantes. Somente o município de Bragança Paulista tem condições de atender às necessidades de saúde nos níveis de maior complexidade ao dispor, em seu território, de ambulatórios e hospitais públicos, além de um complexo universitário privado prestando serviços na área da saúde. Pelas características dos municípios, em particular o pequeno número de habitantes e a baixa capacidade tecnológica local, impunha-se a necessidade de um processo de regionalização solidária, aliada a um forte investimento na formação de seus gestores. A organização do FEP na região surgiu para tentar suprir tais necessidades.

\section{Educação permanente em saúde: uma aproximação ao conceito}

A educação permanente como estratégia pedagógica foi assumida como conceito-chave na década de 1970, a partir da 15a Conferência Geral da Organização das Nações Unidas para a Educação, a Ciência e a Cultura (Unesco). Essa conferência, que tinha como intuito dar nova orientação para os sistemas nacionais de ensino, elaborou 21 princípios norteadores da educação permanente, dos quais destacamos:

- A educação permanente deve ser a pedra angular da política educacional, tanto para países desenvolvidos como para aqueles em desenvolvimento;

- A educação permanente deve ser prolongada durante toda a vida, adquirindo dimensões de movimento popular;

- A educação permanente não tem a finalidade de formar num determinado ramo profissional, mas oferecer recursos para o crescimento do indivíduo (SILVEIRA, 2006).

Seguindo a linha proposta pela Unesco, em 1984, após intensas discussões com representantes dos governos nacionais, e frente aos problemas de fragmentação do saber no campo da saúde, 
em especial na América Latina e no Caribe, a Organização Pan-Americana da Saúde (OPS) resolveu propor a educação permanente em saúde (EPS) como uma estratégia de "identificar a forma ideal de diminuir a fragmentação das ações e saúde e do ensino e ampliar a democracia, buscando a equidade nos serviços de saúde” (HADDAD, 1994, p. 1). O trabalhador passa a ser o principal ator nessa transformação, pois só através da sua conscientização poderiam ser alcançadas mudanças na atenção à saúde da população. Transformar o trabalhador seria a principal preocupação da EPS, tornando-a um instrumento de desenvolvimento social, através das mudanças na atenção à saúde da população (QUINTANA et al., 1994).

A noção de aprender a aprender contida na proposta da EPS e a assunção do trabalho cotidiano como objeto de aprendizagem individual, coletiva e institucional pressupõem processos de ensino-aprendizagem significativos. Para Moreira (2000), a partir de uma visão crítica de educação, "o fato mais importante para a aprendizagem significativa é o conhecimento prévio, a experiência prévia, ou a percepção prévia, e o aprendiz deve manifestar uma predisposição para relacionar de maneira não arbitrária e não literal o novo conhecimento com o conhecimento prévio” (p. 15).

Nessa perspectiva, o Ministério da Saúde (MS), mais especificamente o Departamento de Gestão da Educação na Saúde (DGES), adotou, a partir de 2003, a educação permanente em saúde como uma estratégia fundamental para a formação e desenvolvimento dos trabalhadores do SUS. O MS assumiu essa proposta como uma política de governo através das portarias 198/GM de 13/02/04 e, mais recentemente, reafirmou essa política com a portaria n. ${ }^{\circ}$ 1996/ GM de 20/08/2007 (BRASIL, 2007). A proposta de EPS do MS-DGES tem

Como estratégia de ensino a aprendizagem significativa, a perspectiva de formação de profissionais de saúde, com o objetivo de mudar o panorama da atenção à saúde no país. Através da problematização das situações cotidianas, do envolvimento dos atores, na direção da construção do conhecimento ampliando e buscando a concretização do SUS, na perspectiva democrática de descentralização (MINISTÉRIO DA SAÚDE, 2005).

Para autores como Ceccim (2005) e Merhy et al. (2006), a construção dos coletivos de produção de EPS poderiam propiciar processos nos quais seria possível "desmascarar” as relações que os indivíduos e os grupos estabelecem com as instituições, criando-se, assim, possibilidades de autoanálise e de explicitação em espaços coletivos dos inúmeros atravessamentos (dados pelas relações de poder, posições na equipe, ideologias, classe social, núcleos profissionais, entre outros) a que as práticas e o trabalho em saúde estão submetidos. Segundo Ceccim (2005): 
O desafio da política brasileira foi o de ultrapassar a utilização pedagógica de natureza educacional, da formulação trabalhada pela OPS, relativa à EPS, para implicá-la com o caráter situacional das aprendizagens nos próprios cenários de trabalho da saúde, em todas as suas dimensões, conectando-as às ações contra-hegemônicas necessárias.

A formulação trabalhada pela OPS dá especial atenção à metodologia de avaliação de resultados nos processos de educação permanente, a qual deve contemplar níveis progressivos de complexidade e “objetivação” dos resultados. O primeiro nível diz respeito à caracterização das opiniões dos participantes sobre o processo de educação permanente. Contudo, isso não bastaria, e seria necessário ir para o segundo nível de avaliação, com o objetivo de se avaliar o rendimento dos sujeitos após certo tempo de participação em processos de capacitação. O terceiro nível de avaliação corresponde à avaliação da transferência do aprendizado à prática, ou seja, um sujeito pode completar exitosamente a avaliação da aprendizagem, porém não conseguir aplicar o aprendido no plano prático da ação. Por fim, um último nível que remeteria à avaliação dos resultados ou produtos, seria o mais complexo, pois implica uma avaliação dos contextos reais de atuação dos atores (ROSCHKE, 2006). Se considerarmos a complexidade das organizações de saúde, podemos imaginar como é desafiador cumprir todos esses níveis de avaliação.

O objetivo deste estudo foi avaliar a contribuição da educação permanente para a formação dos gestores municipais de saúde de uma região do Estado de São Paulo, especificamente a estratégia denominada Fórum de Educação Permanente para Gestores Municipais de Saúde (FEP), da Região de Bragança Paulista. A metodologia adotada pelos idealizadores do FEP não explicitou, quando de sua formulação, todos os níveis de avaliação preconizados pela OPS. Na verdade, a proposta de avaliação do fórum só foi definida na pesquisa que gerou o presente artigo, resultado de parceria entre a Universidade Federal de São Paulo e os gestores, e reflete, portanto, a própria metodologia adotada no estudo.

\section{$O$ contexto do estudo}

\section{O funcionamento do Fórum de Educação Permanente}

O órgão regional da SES/SP (DRS-VII), à época do estudo, estava organizado em quatro microrregiões, sendo Bragança Paulista, com seus 11 municípios, uma delas. Uma técnica do DRS-VII era responsável pelas atividades de contato com os gestores municipais, principalmente para cobranças ou encaminhamentos vindos do Ministério da Saúde ou da Secretaria Estadual, mas com pouca atividade de coordenação técnica e política efetiva, o que

CADERNOS GESTÃo PÚBLICA E CIDADANIA, V. 14, N. 55 - JUL./DEZEMBRO DE 2009 
só passou a ocorrer com mais nitidez a partir do funcionamento do FEP. Essa iniciativa nasceu como uma oferta do órgão regional e depois, aos poucos, foi conseguindo a adesão dos gestores municipais. A microrregião transformou-se em uma das “regiões de saúde” criadas pelo Pacto pela Saúde (BRASIL, 2006b).

Participavam do fórum o secretário municipal ou o diretor de saúde - dos 11 municípios, apenas três gestores tinham status de secretário -, membros da equipe dirigente local, muitas vezes funcionários do quadro estável de técnicos e a profissional do DRS-VII. Pesquisadores da Universidade Federal de São Paulo (Unifesp) também participavam dos encontros, compartilhando sua coordenação com o órgão regional. A participação dos pesquisadores se manteve mesmo após o final da pesquisa, prolongando-se até o fim dos mandatos dos gestores municipais (dezembro de 2008). Como será visto adiante, o engajamento dos pesquisadores em todos os encontros resultou em estreita proximidade com os gestores municipais, configurando o que é denominado de observação participante, transformando-se no procedimento metodológico mais importante do estudo, embora não tenha sido o único.

O município que recebia os componentes da reunião mensal do FEP se responsabilizava pela infraestrutura organizacional (espaço físico, equipamentos didáticos, alimentação, entre outros). Cada encontro tinha a duração de aproximadamente seis horas e, quando necessário, era dividido em dois períodos.

O FEP não teve como ponto de partida uma pauta preestabelecida de temas ou conteúdos a serem desenvolvidos, como nos cursos mais tradicionais de formação de gestores. A coordenação (DRS-VII/Unifesp) trabalhava tanto com algumas ofertas de temas - que podiam ser apresentados na forma de uma rápida aula expositiva - como com a escuta das questões ou problemas vividos pelos gestores. Em todas as reuniões, era apresentado um elenco de possibilidades de discussão e, com o amadurecimento do FEP, a pauta do encontro seguinte era definida junto com os próprios gestores.

Uma estratégia pedagógica importante era a definição de "práticas gerenciais” para serem desenvolvidas entre os encontros presenciais mensais, com o objetivo de propiciar aos gestores o entendimento de temas e/ou ajudar na tomada de decisão, como, por exemplo, a identificação de indicadores diversos para ajudar no planejamento e/ou redirecionamento de ações; listagens de especialidades médicas e os gastos financeiros correspondentes; resolutividade e atendimento das demandas da população; articulação com prestadores de serviços de média e alta complexidade; relatos de modelos assistenciais existentes etc. Todos os gestores experimentaram momentos de sistematização e apresentação das “práticas” desenvolvidas em seus municípios. O papel da coordenação era comentar os conteúdos apresentados, estimular 
o debate entre eles e fazer uma síntese teórico-conceitual ao final do encontro. Os temas teóricos surgiam a partir dessas discussões, entre os quais poderiam ser lembrados: a gênese do SUS como política de saúde e seus instrumentos legais; as necessidades de saúde e modelos tecnoassistenciais; programação e planejamento em saúde, em particular o uso de parâmetros para o dimensionamento de necessidades de serviços; a gestão do trabalho médico; vigilância à saúde; protocolos de saúde; regulação em saúde; controle social no SUS; assistência farmacêutica; o papel do hospital no SUS etc. Desse modo, a pauta de conteúdos ia sendo montada na própria dinâmica dos encontros, a partir das necessidades ou dificuldades concretas vividas pelos gestores, de modo coerente com os princípios da educação permanente.

Nos encontros mensais, eram desenhadas estratégias para o possível enfrentamento das situações, principalmente aquelas dependentes de uma melhor pactuação intergestores, em particular novos fluxos de referência e contrarreferência entre os municípios da Região. Frequentemente, o encontro do FEP era desdobrado em alguma reunião de um grupo técnico para o detalhamento de um encaminhamento específico. Na Tabela 1 são apresentados os núcleos temáticos das reuniões durante o período de observação (fevereiro a dezembro de 2006). Nela se pode constatar que a maior dificuldade para esse grupo de gestores era a resolução do acesso dos municípios às ações de média e alta complexidade tecnológica, tema que ocupou metade das reuniões durante o ano de análise.

Tabela 1 - Núcleos temáticos do FEP de Bragança Paulista desenvolvidos em 2006

\begin{tabular}{|l|l|}
\hline \multicolumn{1}{|c|}{ Mês } & \multicolumn{1}{c|}{ Núcleo Temático } \\
\hline Fevereiro & Dificuldades dos gestores municipais com a Média e Alta Complexidade (MAC). \\
\hline Março & $\begin{array}{l}\text { Organização dos serviços de saúde. } \\
\text { Discussão sobre consórcio na microrregião. }\end{array}$ \\
\hline Abril & Apresentação da Universidade São Francisco (USF) ao grupo. \\
\hline Maio & $\begin{array}{l}\text { Gestão do trabalho médico. } \\
\text { Compra de serviços de MAC. } \\
\text { Modelo de atenção à saúde. }\end{array}$ \\
\hline Junho & $\begin{array}{l}\text { Organização do trabalho médico. } \\
\text { Precarização e privatização do trabalho em saúde. }\end{array}$ \\
\hline Julho & $\begin{array}{l}\text { Organização da atenção básica em Bragança Paulista. } \\
\text { Custeio hospitalar. } \\
\text { Privatização da saúde. }\end{array}$ \\
\hline Agosto & $\begin{array}{l}\text { Política de distribuição de cotas da média e alta complexidade pelo Hospital Universitário } \\
\text { de Bragança Paulista. }\end{array}$ \\
\hline
\end{tabular}




\begin{tabular}{|l|l|}
\hline \multicolumn{1}{|c|}{ Mês } & \multicolumn{1}{c|}{ Núcleo Temático } \\
\hline Setembro & $\begin{array}{l}\text { Discussão sobre a Vigilância Sanitária (VISA) e Vigilância Epidemiológica (VE). } \\
\text { Modelo de atenção à saúde em Atibaia. }\end{array}$ \\
\hline Outubro & $\begin{array}{l}\text { Discussão sobre VISA e VE. } \\
\text { Papel do Departamento Regional de Saúde. }\end{array}$ \\
\hline Novembro & Especialidades Médicas e procedimentos de MAC. \\
\hline Dezembro & Avaliação anual do fórum e confraternização. \\
\hline
\end{tabular}

Fonte: SATO, 2008

Nos últimos meses do FEP, foram propostas práticas gerenciais que consistiam em fazer um balanço do que houve de avanços e problemas na gestão que se encerrava e na elaboração de novas estratégias para os próximos anos pelos futuros gestores. Isso era denominado de “exercício de transição republicana”, isto é, tentar inaugurar uma prática de governo que não se pautasse por rupturas quando da mudança periódica dos governantes, mas que conseguisse construir, no tempo, uma política pública como é o SUS.

\section{Uma caracterização dos gestores municipais que participaram do Fórum de Educação Permanente}

Entender quem é o gestor municipal, sua história, sua capacidade de governo, entre outros aspectos, ajuda a compreender algumas características da gestão municipal, em particular a importância do FEP na formação desses gestores. Durante o período de observação, constatou-se que havia uma mudança relativamente frequente dos gestores municipais e que alguns deles eram pouco experientes ou não tinham nenhuma experiência na área de saúde. Dos 11 municípios que compunham o FEP de Bragança Paulista, em seis houve mudança do gestor no decorrer de um ano de acompanhamento, sendo que em dois municípios a troca aconteceu por três vezes.

Entre os nove gestores municipais da Região, três estavam em seu primeiro mandato frente à secretaria/departamento de saúde. Um deles vinha de uma experiência de longos anos no sistema bancário. Outro desfrutava de larga experiência na área de educação pública, facilitando assim sua compreensão dos trâmites burocrático-administrativos do setor público e, mesmo sem formação específica sobre a gestão em saúde e/ou política de saúde, podia estabelecer alguns paralelos entre saúde e educação. Apenas dois gestores tinham formação e experiência em gestão de serviços de saúde, porém não participavam com frequência das reuniões dos FEPs. 
A não valorização do controle social no SUS e sua importância na definição e destinação de verbas para a saúde, a baixa capacidade técnica, política e gerencial, fruto da inexperiência e despreparo desses gestores na gestão da saúde, agravadas pela intensa troca de dirigentes da saúde, justificavam a necessidade de estratégias de formação desses quadros.

Outro traço importante do perfil desses atores é que o cargo de gestor municipal de saúde é fundamentalmente político. A indicação por compromissos com as forças políticas partidárias do próprio município é a regra e sobrepuja, na maioria das vezes, a preocupação com a construção do projeto ético, político e social expresso nos princípios e diretrizes do SUS. A contratação de parentes e amigos para os cargos de gestão criava a figura do "gestor de fachada”, ou seja, o gestor ocupa formalmente o cargo, mas a gestão da secretaria é feita, de fato, por técnicos estáveis do seu quadro. O nepotismo é bastante comum, pois vários gestores guardam algum grau de parentesco com o prefeito.

\section{Metodologia}

A pesquisa de caráter qualitativo, um estudo de caso (YIN, 2005), é parte integrante de uma pesquisa maior intitulada "O gestor estadual e os gestores municipais na construção do sistema locorregional de saúde: desafios da gestão descentralizada do Sistema Único de Saúde (SUS)", doravante denominada de "pesquisa-mãe” e realizada com recursos CNPq/ FAPESP, de 2005 a2007 (CECILIO et al., 2007). Uma das técnicas de coleta de dados da pesquisa-mãe foi a observação participante dos pesquisadores em dois fóruns de educação permanente existentes na região de Campinas, sendo um deles o de Bragança Paulista. A participação nos fóruns revelou-se tão rica em si mesma, propiciou um envolvimento tão próximo com os gestores, que acabou gerando a dissertação de mestrado de uma das pesquisadoras da Unifesp e permitiu uma reflexão sobre o processo de educação permanente que se apresenta no presente artigo.

A observação participante é uma técnica de pesquisa que resulta em processo construído duplamente pelo pesquisador e atores sociais envolvidos. Quase sempre marcada por relações informais do pesquisador no campo, essa informalidade é apenas aparente, à medida que se reveste de pressupostos, cuidados teóricos e práticos, que podem fazer avançar ou prejudicar o conhecimento da realidade. O observador participante é, ao mesmo tempo, parte do contexto em observação, modificando e sendo modificado por ele. O pesquisador deve disponibilizar-se a viver no contexto, aberto à realidade do grupo pesquisado (MINAYO, 1994).

CADERNOS GESTÃo PÚBLICA E CIDADANIA, V. 14, N. 55 - JUL./DEZEMBRO DE 2009 
Por outro lado, a pesquisa se filia ao campo teórico marcado pelos seguintes princípios: a) a explicação não é entendida como verificação objetiva de hipóteses, mas como um processo de produção do conhecimento que se adapta progressivamente através da interação entre observador e observado (MELUCCI, 2005); b) se a pesquisa social ignora ou desconsidera totalmente a alteridade (a relação como os atores institucionais), ela é condenada a fechar-se em uma cilada, reduzindo-se, nos casos mais graves, a uma atividade totalmente autorreferenciada, incapaz de explorar mundos sociais e realidades inéditas (RANCI, 2005); e c) o impacto do conhecimento nesse tipo de investigação é inseparável de uma ação de comunicação de resultados, através da qual se consegue modificar a compreensão dos interessados sobre seu contexto. A produção do conhecimento e sua utilização na prática estão intimamente ligadas (FRIEDBERG, 1993).

Pretendia-se, pois, uma metodologia de investigação que conseguisse produzir um conhecimento que fosse apropriado, imediatamente, pelos atores da pesquisa, buscando contribuir para o enfrentamento de problemas concretos que vivem na função de gestores de sistemas locais de saúde.

O período analisado está restrito ao ano de 2006, perfazendo a participação e observação de 11 encontros. Dados obtidos na pesquisa-mãe, em particular os resultados de dois grupos focais realizados com os gestores municipais e entrevistas com dirigentes do DRS-VII, também foram utilizados no momento de análise, à medida que propiciaram uma compreensão, sob outros ângulos, das contribuições do FEP na formação dos gestores.

Para a coleta de dados, utilizou-se de um diário de anotações - diário de campo - e, com o decorrer do estudo, algumas reuniões do FEP foram gravadas em fita magnética, depois transcritas para leitura e análise. No diário de campo foram registradas as impressões do pesquisador sobre funcionamento do FEP e, em particular, anotações sobre as pautas propostas, os temas desenvolvidos, as discussões feitas e os encaminhamentos realizados, além de notas sobre as posturas e considerações dos gestores municipais. Utilizando-se das anotações do diário de campo, foram elaborados relatórios mensais organizados com os seguintes tópicos: pauta do dia; participantes da reunião (gestores, membros da equipe de gestão municipal, representantes do DRS-VII, outros presentes); local de realização da reunião; tema desenvolvido no encontro; descrição das discussões ocorridas na reunião; encaminhamentos e uma apreciação global da pesquisadora sobre o encontro.

A pesquisa foi aprovada pelo Comitê de Ética da Universidade Federal de São Paulo e todos os participantes assinaram um termo de consentimento livre e esclarecido. 


\section{Resultados}

Pode-se afirmar, inicialmente, que o processo de educação permanente dos gestores municipais envolve várias dimensões, conforme se depreende da sistematização e análise do material empírico: a) uma dimensão de autoanálise dos gestores, ao aumentar a reflexão sobre o seu próprio trabalho (fazer gestão) de forma compartilhada com outros atores na mesma situação de governo; b) uma dimensão pedagógica, ao aumentar a "caixa de ferramentas" composta por saberes operatórios, de base mais instrumental, para a gestão; e c) uma dimensão política, ao melhorar a compreensão da trajetória histórica do SUS como política de saúde, em particular seus determinantes e sua localização no quadro mais amplo do papel do Estado. A melhor articulação entre os gestores municipais, aumentando sua capacidade de mobilização e pressão junto ao gestor estadual, também pode ser vista nessa dimensão.

Para fins de clareza, a apresentação dos resultados do FEP foi organizada em três blocos temáticos: 1) contribuições para uma melhor compreensão do papel do gestor municipal na atual etapa do SUS; 2) contribuições para uma melhor articulação política dos gestores municipais, aumentando sua governabilidade tanto local como perante o gestor estadual; e 3) contribuições para aumentar a “caixa de ferramentas” conceitual e operatória dos gestores.

\section{Uma melhor compreensão do papel do gestor municipal e sua responsabilidade local para implementação da política de saúde}

Alguns gestores referem que seu primeiro contato teórico com o Sistema Único de Saúde aconteceu a partir desses encontros e que, desde então, passaram a ter outro olhar para a Saúde Pública. Essa mudança vem possibilitando atuar de forma mais esclarecida na gestão da saúde de seu município. A seguinte fala de um gestor, avaliando a contribuição do fórum para sua formação, ilustra bem a situação acima relatada: "É assim, eu fui lançado, também, no departamento de saúde, na fogueira, numa gestão que começou na prefeitura [...] há dois anos e eu sou o terceiro gestor, terceiro diretor de saúde... Eu confesso, eu não sabia nada. Eu sou recém-formado, me formei em [...]. A noção que eu tinha do SUS era uma coisinha bem [pequena] e eu não sabia nada de nada”. Essa é uma indicação da importância desses encontros e do quanto os gestores carecem de formação gerencial e conhecimento da política nacional de saúde, no sentido de conhecer o próprio SUS, conforme reiterado por mais de um participante do FEP, em várias oportunidades.

Destacamos aqui uma das reuniões do FEP, quando um gestor relata que melhorou seu entendimento sobre seu papel de gestor municipal, graças à sua participação no fórum. Em

CADERNOS GESTÃo PÚBLICA E CIDADANIA, V. 14, N. 55 - JUL./DEZEMBRO DE 2009 
54 A EDUCAÇÃO PERMANENTE EM SAÚDE COMO ESTRATÉGIA DE FORMAÇÃO DE GESTORES MUNICIPAIS:

O FÓRUM DE EDUCAÇÃO PERMANENTE DE BRAGANÇA PAULISTA

suas palavras: "[Houve] um aprendizado permanente, que considera como educação permanente, pois não conhecia minhas obrigações (leis, portarias, decretos e normas que regulamentam o setor saúde)”.

Apesar de o FEP não ter partido de uma pauta fechada de temas que desse conta de todo o complexo universo do cotidiano dos gestores, com o correr dos encontros uma agenda de "importâncias" foi sendo construída. Essa dinâmica foi estimulando os gestores, como afirmavam em seus depoimentos, a ficar mais atentos a temas que antes lhes passavam despercebidos. Em mais de uma oportunidade houve gestor que afirmava "não sei o que eu faria se não tivesse esse espaço do fórum para me apoiar”.

\section{Uma melhor articulação política dos gestores municipais, aumentando sua governabilidade tanto local como perante o gestor estadual}

A criação de relações de confiança e troca entre todos os participantes do fórum pode ser vista como uma contribuição positiva dessa estratégia pedagógica, propiciando o compartilhamento de problemas e de suas respectivas soluções. $\mathrm{O}$ fato de se encontrarem periodicamente, cada vez em um dos municípios, e conversarem sobre seus problemas, os fortalecia. Um bom exemplo disso foi o modo organizado como se posicionaram, a partir das discussões no FEP, perante o hospital universitário localizado no município-sede da região, resultando numa melhor sistematização do acesso dos usuários (vindos de toda a região) às especialidades médicas e exames mais complexos oferecidos pelo hospital.

Uma dificuldade vivida no FEP foi a pouca participação dos secretários de saúde dos municípios maiores, muitas vezes com mais autonomia política, financeira e administrativa para resolver os problemas de saúde da sua cidade. Essa ausência dos colegas nas reuniões, quase sempre substituídos por alguém de sua equipe, era motivo frequente de queixas dos participantes.

Os gestores municipais atribuem ao FEP mudanças percebidas em sua relação com os membros da DRS-VII, seja a partir de um entrosamento maior entre eles, seja no modo de enfrentamento de problemas próprios da regionalização. A fala de um gestor ilustra essa transformação: "Hoje é diferente de um ano atrás: hoje a situação está mudando", comparando a situação daquele momento em relação ao início do fórum um ano antes. Aqui, o gestor fala das difíceis relações com o órgão regional, sempre visto como instância de cobrança e ameaças. A presença da representante do DRS-VII em todos os encontros parece ter facilitado a aproximação dos gestores municipais com o gestor estadual.

CADERNOS GESTÃo PÚBLICA E CIDADANIA, V. 14, N. 55 - JUL./DEZEMBRO DE 2009 
Segundo Merhy, Feuerwerker e Ceccim (2006), “uma das finalidades da EPS, portanto, seria a contribuição para que cada coletivo possa conquistar a capacidade de ser seu próprio coautor por meio de um processo de reinvenção das instituições de saúde” (p. 154). Nesse sentido, o coletivo representado pelos gestores e equipes de gestão que constituem o FEP foi capaz, em boa medida, de produzir pactos e acordos que desdobraram em propostas e projetos potentes para transformar algumas práticas de saúde da região, operando em realidades “vivas”, através da ação dos atores em cena e por meio da construção de relações de confiança e responsabilidade assumida pelos sujeitos desse coletivo.

O FEP foi se tornando, com o correr dos encontros, espaço político de articulação e formação, de alguma forma substituindo o papel que deveria ser do gestor estadual, através de seu órgão regional.

\section{Um enriquecimento da “caixa de ferramentas” conceitual e operatória dos gestores}

Em um dos momentos de avaliação do FEP, um gestor relatou que veio da área da educação e constatou sua dificuldade em decifrar as siglas: "Você vai vivenciando as estruturas, as mudanças, no meu caso em educação, as leis novas, as novas estruturas, os novos processos de alfabetização. Você foi vivenciando. É o que aconteceu com esse pessoal que [está] aqui com um ano de janelinha [no fórum]! Mas eu... É PIB, PAB, POB... Até a terminologia, até a gente se familiarizar, não é fácil! Então você vê, o fórum nasceu com a preocupação da [formação dos gestores]. (...). Nota mil pro fórum, se não fosse o fórum, eu acho que a metade já tinha desistido da função de gestor”.

Até mesmo a terminologia e o uso excessivo de siglas, razoavelmente tranquilo para quem está há muito tempo no SUS, causa estranheza e dificuldades para os novos gestores que, como se viu, nem sempre são oriundos da área da saúde. Um gestor chegou a produzir - e levar para um dos encontros - um pequeno glossário que havia elaborado sobre as siglas existentes na área da saúde e que facilitava seu trabalho, uma vez que sua origem profissional era a área de administração de empresa privada na área educacional. Esses depoimentos vão ao encontro das discussões apresentadas por autores que falam da sobrecarga de responsabilidades, da necessidade de investimentos nesses gestores que, em geral, não estão preparados para arcar com a quantidade de atribuições que lhes são conferidas e ainda com o agravante da falta de formação na área das políticas de saúde.

A coordenadora da região de saúde fez o seguinte relato em uma reunião de avaliação da coordenação do FEP (DRS-VII/Unifesp): “O que me anima é que desde que eu [comecei a 
acompanhar], no início do fórum de [....], que os gestores vêm crescendo e vêm dando contribuição. Mesmo na gestão dos municípios [...]. Como eles estão crescendo com o fórum! E eles falam muito isso, que antes do fórum era uma coisa e agora eles cresceram. E eu também cresci muito, aprendi muito com eles e todo mundo, [...] E anima, também, a participação deles lá na CIR com mais intensidade”. A CIR era a Comissão Intergestores Regional que existiu até o Pacto pela Saúde, da qual participavam todos os gestores dos municípios que compõem o DRS-VII. O diretor do DRS-VII, em entrevista realizada para a pesquisa-mãe, reconheceu explicitamente que "a participação dos gestores no FEP mudou o caráter da participação deles nas reuniões da CIR; agora estão mais atentos e atuantes”.

Por fim, eram frequentes os relatos, nas próprias reuniões do FEP, de como os gestores se apropriavam da experiência apresentada nos encontros anteriores e buscavam aplicá-la em seus municípios. Com o correr do tempo, foram se tornando frequentes as visitas de gestores entre si, nos intervalos dos encontros, para conhecer com mais detalhe alguma inovação na gestão que lhes havia interessado. A coordenação do fórum adotava como orientação dar destaque a toda experiência bem-sucedida em qualquer dos municípios, utilizando-se dela para propor novas intervenções. Alguns exemplos dessas trocas entre os gestores: a utilização de protocolos de cuidados com hipertensos e diabéticos e adoção de ações programáticas para qualificar o cuidado; mecanismos de regulação da utilização de exames de média e alta complexidade e de encaminhamento para especialistas; e mecanismos de gestão do trabalho médico, em particular a apropriação de alguns indicadores de produtividade, entre os quais a relação entre exames solicitados e consultas realizadas. Sempre havia alguma experiência mais qualificada nos vários municípios e o FEP se tornou, com o tempo, uma espécie de "mercado" de troca de tecnologias de gestão e de organização do cuidado.

\section{Discussão}

A municipalização foi uma das bandeiras mais importantes do movimento sanitário brasileiro em sua luta pela reordenação do setor da saúde no Brasil. Trazia implícita a ideia de que a gestão do setor saúde, feita no nível municipal, seria um facilitador do controle social, pelo melhor acesso dos cidadãos e suas demandas aos seus governantes. Hoje, já temos a compreensão de que as coisas não eram tão simples assim. O estudo permite apontar que muitas variáveis têm contribuído para relativizar a aposta que se fazia no processo de municipalização, entre as quais o despreparo e a alta rotatividade dos gestores, a ingerência político-partidária na saúde e a quase ausência de mecanismos regionais de coordenação, além do bem conhecido problema de subfinanciamento do setor (SANTOS, 2007).

CADERNOS GESTÃo PÚBLICA E CIDADANIA, V. 14, N. 55 - JUL./DEZEMBRO DE 2009 
O despreparo e a rotatividade dos gestores municipais poderiam inviabilizar a pretensão de processos de educação permanente, contínuos no tempo? Essa foi uma interrogação muito presente no correr de todo o estudo. Houve uma visível rotatividade de parte importante dos gestores no correr do ano observado. Por outro lado, houve uma boa estabilidade de membros das equipes gestoras municipais, compostas, quase sempre, por pessoal dos quadros permanentes dos municípios e que parecia resistir às mudanças tão frequentes dos gestores. Uma indicação que o estudo permite fazer é que futuras iniciativas parecidas com o FEP devam ter especial cuidado com a incorporação e valorização dos quadros estáveis. Assim será possível contribuir para a construção de uma tecnoburocracia detentora de uma "caixa de ferramentas" conceitual e operatória, que se transforme em patrimônio técnico dos sistemas locais de saúde, contribuindo para alguma qualificação da gestão municipal em contextos mais desfavoráveis.

A maior contribuição do FEP parece ter sido possibilitar a construção de um espaço político no qual foram exercitadas formas mais solidárias de relacionamento, tanto entre os gestores entre si, como entre eles e o gestor estadual. Diante da evidente falta de protagonismo do órgão regional da Secretaria de Estado da Saúde na articulação de uma política regional de saúde, o FEP de alguma forma se antecipou à proposta dos “colegiados regionais”, criados pelo Pacto pela Saúde, em 2007, propiciando ambiente favorável ao exercício de formas de regionalização mais solidárias.

Há indicações de precarização da força de trabalho na região, que precisaria ser mais bem caracterizada em outras investigações. Precarização entendida como a utilização de força de trabalho sem vínculo formal com a instituição e, por consequência, sem a garantia dos direitos trabalhistas garantidos pela legislação. Um bom exemplo disso é a “contratação” de médicos como "autônomos" através de "empresas" de fachada, muitas vezes de propriedade de um médico com boa articulação na região. Foi visto, no espaço do FEP, como muitos gestores estão terceirizando os serviços de saúde, entregando-os à iniciativa privada, com o objetivo de reduzir gastos, tendo como justificativa a Lei de Responsabilidade Fiscal. Uma consequência disso é que os trabalhadores contratados para prestação de serviço nos municípios não são da responsabilidade direta do gestor municipal de saúde. Um dos municípios já estava com toda a assistência à saúde terceirizada, inclusive a rede básica. O que significa ser gestor de saúde nessa situação? O que ele governa de fato? No limite, ele passaria a ser um fiscal com a responsabilidade de supervisionar os contratos de prestação de serviços? 


\section{Conclusões}

Dois questionamentos poderiam encerrar o artigo: a) qual a reprodutibilidade em outros contextos da experiência que está sendo analisada aqui?; e b) o aprendizado dos gestores ao participarem no FEP impacta, de fato, a micropolítica dos sistemas municipais de saúde, produzindo mudanças reais na organização dos processos de trabalho que resultem em melhor assistência para os usuários?

Em relação à primeira pergunta, é possível afirmar que os recursos mais importantes para a criação e manutenção de um fórum de educação permanente, nos moldes da experiência aqui relatada, são: a vontade política e a adesão dos gestores à proposta e a existência de uma coordenação com formação, experiência e legitimidade junto aos gestores para conduzir os trabalhos. Os demais recursos logísticos - local para o encontro, alimentação e transporte foram bancados, de forma solidária, pelos próprios municípios e não constituíram problemas para a viabilização da estratégia.

Considerando que os processos de educação permanente são bastante "abertos", isto é, trabalham com uma metodologia pedagógica problematizadora e significativa, que se expressa na composição de pautas e temas a partir dos interesses dos participantes, a coordenação precisa estar apta e ter traquejo para fazer uma boa escuta da dinâmica dos encontros, promovendo sínteses, propondo temas de estudo e reflexão e, sempre que necessário, aportando conteúdos teóricos adequados para o momento. Nessa medida, a competência e o preparo da coordenação tornam-se o recurso vital para o sucesso do programa. O FEP tinha um desenho bem diferente dos cursos de especialização em gestão tradicionais, organizados com temas preestabelecidos, na forma de aulas, com bibliografia definida já no programa, de modo que a coordenação sempre teve algum controle sobre o desenrolar do curso. A educação permanente é uma construção que vai sendo feita no encontro com os participantes e, por isso, exige bem mais flexibilidade e experiência de quem faz a coordenação.

Uma discussão que esteve sempre presente na condução do FEP é se ele devia adotar uma pauta mais fechada e predefinida de temas obrigatórios a serem desenvolvidos, tendo em vista o despreparo dos gestores e a heterogeneidade de formação que eles traziam, ou se poderia trabalhar com uma pauta mais aberta, construída em contexto e com os gestores, a partir de suas dificuldades. No caso de prevalecer a primeira concepção, o FEP deveria ter uma definição prévia de "competências" a serem adquiridas, o que permitiria processos mais estruturados de avaliação do próprio processo de formação dos gestores. No caso que está sendo analisado, não houve, de fato, uma definição prévia de conteúdos e competências, mas a coordenação sempre

CADERNOS GESTÃo PÚBLICA E CIDADANIA, V. 14, N. 55 - JUL./DEZEMBRO DE 2009 
trabalhou com "ofertas" de alguns temas que avaliava como sendo importantes para os gestores, quasesempreodesdobramentoda discussãodealgumproblemareal. Olhandoretrospectivamente, e revendo os temas desenvolvidos, pode-se verificar que se compôs um "programa" de estudos bastante abrangente, embora os temas não apresentassem um encadeamento "lógico" que os programas mais tradicionais de formação em gestão oferecem.

Nesse sentido, o objetivo do estudo de avaliar a contribuição da educação permanente para a formação dos gestores municipais de saúde fica condicionado, ou subordinado, à própria dinâmica do FEP. Os idealizadores do fórum não explicitaram, quando de sua idealização, uma metodologia de avaliação que desse conta de todos os níveis de complexidade, como preconizado pela OPS. Isso quer dizer que não seria possível fazer uma avaliação estruturada do maior ou menor sucesso do fórum pelo grau de alcance de competências ou conteúdos previamente estabelecidos e, mais do que isso, sua capacidade de provocar alterações efetivas no plano das ações governamentais nos municípios participantes. $\mathrm{O}$ alcance maior do fórum parece ter sido, como mostram os resultados, a produção de um coletivo de gestores com maior capacidade de articulação, compreensão do seu “papel de gestor” e, em algumas situações, o desencadeamento de ações gerenciais nos seus municípios. Trata-se, pois, de estudo conduzido no SUS, no qual se buscou produzir uma "validação de resultados" junto aos atores institucionais diretamente envolvidos, no sentido de se reconhecerem nos achados da pesquisa e de se apropriarem deles para transformações em suas práticas, como um coletivo em ação transformadora.

Junto da criação das regiões de saúde previstas no Pacto pela Saúde (BRASIL, 2006b), veio a diretriz da adoção de processos de educação permanente dos gestores das regiões, nos moldes do que foi experimentado no FEP de Bragança Paulista. Uma das dificuldades para a proposta foi a constatação de que não havia, nos órgão regionais da Secretaria de Estado da Saúde, profissionais preparados para assumir os processos de educação permanente nas regiões. Para superar tal limitação, o Ministério da Saúde, em parceria com algumas instituições privadas, tem promovido cursos para formação de “facilitadores” desses processos junto às microrregiões. O FEP de Bragança Paulista só foi viabilizado através de uma parceria com a Universidade Federal de São Paulo e, nesse sentido, foi pioneiro, antecipou-se, e pode oferecer algum exemplo para esse novo momento do SUS, sendo essa sua pretensão maior.

A segunda pergunta, qual seja, se o aprendizado dos gestores no FEP impacta na vida de suas secretarias, promovendo transformações visando aprimorar os processos de trabalho e suas práticas organizacionais, o recorte metodológico do estudo não permite responder com segurança, apesar dos vários relatos de mudanças positivas nos sistemas locais de saúde feitos pelos gestores, como vimos antes. De qualquer forma, é necessário reconhecer que há, sempre, 
resistência por parte dos trabalhadores para transformar suas práticas na direção desejada pelos dirigentes, o que coloca o desafio de praticamente desdobrar o processo de educação permanente vivido pelos gestores no FEP para um conjunto mais amplo de atores institucionais.

\section{Referências}

BRASIL (Ministério da Saúde). Norma Operacional Básica do Sistema Único de Saúde NOB-SUS-93. Brasília, DF: Ministério da Saúde, 1993.

BRASIL (Ministério da Saúde). Departamento de Gestão da Educação na Saúde. A educação permanente entra na roda: polos de educação permanente: conceitos e caminhos a percorrer, p. 1-35. Secretaria de Gestão do Trabalho e da Educação na Saúde. Brasília: Editora do MS. 2005.

BRASIL (Ministério da Saúde). Secretaria-Executiva. Departamento de Apoio à Descentralização. Regionalização Solidária e Cooperativa: orientações para sua implementação no SUS. 44 p. Série Pactos pela Saúde, v. 3, 2006. Brasília: Editora MS, 2006.

BRASIL (Ministério da Saúde). Portaria/GM 399, de 22.02.2006. Divulga o Pacto da Saúde 2006 - Consolidação do SUS e aprova as Diretrizes Operacionais do Referido Pacto. Ministério da Saúde, Brasília, DF, 2006.

BRASIL (Ministério da Saúde). Portaria GM 1996, de 20.08.2007. Dispõe sobre as diretrizes para implementação da Política Nacional de Educação Permanente em Saúde. Diário Oficial da União. Brasília DF, 22 de agosto de 2007. Brasília DF: Impressa Oficial. Edição 162, seção 162 .

CECCIM, R. B. Educação Permanente em Saúde: desafio ambicioso e necessário. Interface, Comunicação, Saúde e Educação, v. 9, n. 16, p. 161-67, 2005.

CECILIO, L. C. O. et al. O gestor municipal na atual etapa de implantação do SUS: características e desafios. Revista Eletrônica de Comunicação, Informação e Inovação na Saúde, v. 1 n. 2, p. 200-207, 2007.

CONSELHO NACIONAL DE SAÚDE. Resolução n. ${ }^{\circ} 335$ de 27.11.2003. Afirma a Política Nacional de Formação e Desenvolvimento para o SUS [...]. DOU. Poder Executivo, Brasília, DF, 05.02.2004.

FRIEDBERG, E. O poder e a regra: dinâmicas da ação organizada. Lisboa: Instituto Piaget, 1993. $230 \mathrm{p}$. 
HADDAD, J. Q. Elementos para el análisis y la caracterización del contexto en que se dan los procesos educativos en los servicios de salud: tendencias y perspectivas. In: HADDAD J. Q.; ROSCHKE, M. A. C.; DAVINI, M. C. (Eds.) Educación permanente del personal de salud. Washington, DC: OPS, 1994. p. 1-30.

LEVICOVITZ, E.; LIMA, L. D.; MACHADO, C. V. Política de saúde nos anos 90: relações intergovernamentais e o papel das Normas Operacionais Básicas. Ciência \& Saúde Coletiva, v. 6, n. 2, p. 269-291, 2001.

MELUCCI, A. Por uma sociologia reflexiva: pesquisa qualitativa e cultura. Petrópolis: Vozes, 2005. 183 p.

MERHY, E. E.; FEURWERKER, L. C. M.; CECCIN, R. B. Educación permanente en salud: una estrategia para intevernir en la micropolítica del trabajo em salud. Salud Coletiva, v. 2, n. 2, p. 147-60, 2006.

MINAYO, M. C. S. Introdução à metodologia de pesquisa social. In: MINAYO, M. C. S. O desafio do conhecimento: pesquisa qualitativa, 3. ed. Rio de Janeiro/São Paulo: HucitecAbrasco, 1994. p. 22-88.

MOREIRA, M. A. Aprendizagem significativa subversiva. Encontro Internacional sobre Aprendizagem, 3, 2000, Lisboa. Lisboa: Atas, 2000.

NEPESS (Núcleo de Estudos e Pesquisas de Sistemas de Saúde). Estudo analítico e prospectivo sobre as relações entre concepção de distrito sanitário e as diretrizes de regionalização expressas na NOAS (Relatório Técnico). São Paulo, 2006, 173 p.

PESTANAM.; MENDES E. V.Operacionalização da regionalização cooperativa. In: PESTANA M.; MENDES E. V. Pacto de gestão: da municipalização autárquica à regionalização cooperativa. Belo Horizonte: Secretaria de Estado da Saúde de Minas Gerais, 2004, p. 55-71.

QUINTANA, P. B.; ROSCHKE, M. A. C.; RIBEIRO, E. C. O. Educación permanente, proceso de trabajo y calidad de servicio en salud. In: HADDAD J. Q.; ROSCHKE, M. A. C.; DAVINI, M. C. (Eds.) Educación permanente del personal de salud. Washington, DC: OPS, 1994, p. 33-61.

RANCI, C. Relações difíceis: a interação entre pesquisadores e atores sociais. In: MELUCCI, A. (Org.) Por uma sociologia reflexiva: Pesquisa qualitativa e cultura. Petrópolis: Vozes, 2005, p. 43-66.

ROSCHKE, M. A. (Ed.) Evaluación en procesos de educación permanente y evaluación en salud: experiencias y lecciones. Washington, DC: OPS, 2006.

CADERNOS GESTÃo PÚBLICA E CIDADANIA, V. 14, N. 55 - JUL./DEZEMBRO DE 2009 
SANTOS, N. R. Desenvolvimento do SUS, rumos estratégicos e estratégias para visualização dos rumos. Ciência \& Saúde Coletiva, v. 12, n. 2, p. 429-437, 2007.

SATO, W. N. S. Fórum de Educação Permanente com estratégia de capacitação dos gestores municipais de saúde. Dissertação de Mestrado em Saúde Coletiva da Universidade Federal de São Paulo, 2008.

SCATENA, J. H. G.; TANAKA, O. Y. Os instrumentos normatizadores (NOB) no processo de descentralização da saúde. Saúde e Sociedade, v. 10, n. 2, p. 47-74, 2001.

SILVA, S. F. Municipalização da Saúde. In: SILVA, S. F. Municipalização da saúde e poder local: sujeitos atores e políticas. São Paulo: Hucitec, 2001, p. 49-87.

SILVEIRA, Z. S. Educação profissional no Brasil: da industrialização ao século XXI. Disponível em: http://www.educacaopublica.rj.gov.biblioteca/educacao/educ109.htm. Acesso em: 11 set. 2006.

VIANA, A. L. A. et al. Descentralização no SUS: efeitos da NOB SUS 01/96. In: NEGRI, B; VIANA, A. L. A. (Orgs.) O Sistema Único de Saúde em dez anos de desafio. São Paulo: Sobraviem/Cealag, 2002, p. 471-488.

YIN, R. K. Estudo de Caso: planejamento e métodos, 3. ed. Porto Alegre: Bookman, 2005, 87 p.

Artigo recebido em 24/09/2009. Aprovado em 24/11/2009. 